\title{
Clival defect in the pathogenesis of recurrent meningitis: a case report and literature review
}

\author{
Ahmet Naci Emecen ${ }^{1,2^{*}}$, Reyhan Ertekin ${ }^{1}$, Begumhan Baysal ${ }^{3}$, Ferhat Arslan ${ }^{1}$ and Haluk Vahaboglu ${ }^{1}$
}

\begin{abstract}
Background: Meningitis is a life-threatening infection often associated with high morbidity. Recurrent bacterial meningitis poses a clinical challenge, both clinically and diagnostically. To prevent further recurrences, the underlying causes of recurrent bacterial meningitis should be investigated intensively.

Case presentation: Here, we aim to present a patient referred to our clinic with rhinorrhea and found to the Staphylococcus aureus meningitis related to a clival defect. The patient reported no history of trauma, surgery, or brain neoplasm, and the cerebrospinal fluid leakage was classified as spontaneous. The patient had two episodes of meningitis in the last 4 years, but etiologic data of the previous episodes were absent. A pneumococcal vaccine was administered following her second attack, suggesting a possible Staphylococcus aureus infection due to altered colonization in the sinuses. She was successfully treated with linezolid but refused surgery to correct the defect and was discharged without neurologic sequelae.

Conclusion: Spontaneous cerebrospinal fluid leakage from the clivus which could provoke recurrent meningitis is a rare situation. In conjunction with appropriate rapid antibiotherapy for the prevention of recurrent meningitis, the removal of anatomical risk factors should be a principal aim. Effective surgical procedures prevent recurrences.
\end{abstract}

Keywords: Clivus, Rhinorrhea, Staphylococcus aureus, Recurrent meningitis, Pneumococcal polysaccharide vaccine

\section{Background}

Recurrent bacterial meningitis is defined as either two or more episodes of meningitis caused by a different bacterial organism or a second or subsequent episode caused by the same organism with a greater than 3week interval following the completion of the initial therapy [1]. The causes of underlying anatomic, immunologic, or chronic parameningeal infections need to be investigated intensively to prevent further recurrence. The clivus is found in the deepest region of the skull base with one of its walls adjacent to the top of the sphenoid sinus. Cerebrospinal fluid (CSF) leakage from the clivus could lead to recurrent meningitis. In this report, we have discussed this rare anatomic defect

\footnotetext{
* Correspondence: ahmetemecen@gmail.com

${ }^{1}$ Department of Infectious Diseases and Clinical Microbiology, Istanbul Medeniyet University, Istanbul, Turkey

${ }^{2}$ Department of Public Health, Epidemiology Subsection, Dokuz Eylul

University School of Medicine, Izmir, Turkey

Full list of author information is available at the end of the article
}

and etiologic differentiation in a patient with recurrent bacterial meningitis in conjunction with relevant reported adult cases from the literature.

\section{Case presentation}

A 64-year-old female was admitted to the emergency room with headache, nausea, and vomiting. Medical history revealed two meningitis episodes: the first being 4 years and the second 2 years previously. Medical data concerning these episodes were absent, but she had been successfully treated with intravenous antibiotics. She was vaccinated with 23-Valent Pneumococcal Polysaccharide Vaccine (PPSV23) following the second meningitis attack. She declared no head trauma, surgery, malignancy, or sinus and ear infections. Beta-lactam allergy was confirmed. Her temperature was $38.3^{\circ} \mathrm{C}$, and she was conscious and oriented. No signs of meningeal irritation were detected, and other system examinations were normal. Her white blood cell (WBC) count was $12,300 / \mathrm{mm}^{3}$ and C-reactive protein level was $1.3 \mathrm{mg} / \mathrm{dl}(<0.5$, normal 
reference). Lumbar puncture revealed elevated opening pressure, cloudy appearance of CSF with 1856 WBC ( $90 \%$ polymorph), CSF glucose was $29 \mathrm{mg} / \mathrm{dl}$ (serum glucose was $112 \mathrm{mg} / \mathrm{dl}$ ), and CSF protein was $98.4 \mathrm{mg} / \mathrm{dl}$. CSF Gram stain showed the appearance of Grampositive cocci in clusters. Linezolid $2 \times 600 \mathrm{mg}$ was started due to the beta-lactam allergy with the diagnosis of acute bacterial meningitis. Methicillin-sensitive Staphylococcus aureus was isolated in CSF culture. Her immune system tests were normal. Computed tomography and magnetic resonance imaging of the skull base revealed irregular millimetric bone defects at the clivus (Fig. 1) and excessive pneumatization of the sphenoid bone posteriorly (Fig. 2). A CSF leak was located in the posterior part of the clivus. Rhinorrhea was questioned and confirmed with $\beta-2$ transferrin analysis. Surgery was offered to repair the clival defect, but she rejected any surgical interventions. After 2 weeks of linezolid treatment, the patient was discharged without neurologic sequelae. Her 6-month follow-up showed no further sign of meningitis.

\section{Discussion}

Our patient has experienced three episodes of meningitis over the last 4 years. The predisposing factor appears to be spontaneous CSF leakage (S-CSF-L) at the posterior part of the clivus. This was based on no other definable history, such as trauma, surgery, or brain neoplasm. The definite cause of S-CSF-L remains elusive. Most cases, however, do have increased intracranial pressure [2]. Pneumatization of the sphenoid bone in conjunction with functional factors, such as the increased intracranial hypertension, continuous erosive effect of CSF and pulsative arteries, and/or other congenital developmental factors, are likely associated with spontaneous CSF leaks [2, 3].

The prevalence of S-CSF-L of all CSF fistulas in any location is between 3 and $40 \%$ in the series [4-7]. S-CSF-L is usually observed at the cribriform plate of the skull base. Sphenoidal and, more specifically, clival localization is even less common [3]. S-CSF-L from the clivus is very rare, with few cases reported in the literature $[6,7]$. Meningitis is the most serious clinic complication in these cases.

CSF leakage due to primary defects and/or fracture of the clivus, or osteomyelitis of the clivus might lead to meningitis and recurrent meningitis [5-13]. Table 1 summarizes the published characteristics of meningitis cases that include clivus defects. Because of the localization, fractures of the clivus are very rare and defined in only one case [10]. The common feature of all cases, except the one with the clivus osteomyelitis, is that patients present with rhinorrhea prior to meningitis. The preferred surgical procedure to repair the leak is endoscopic endonasal transsphenoidal surgery. No recurrence of the leak or meningitis has been reported following this type of surgery.

In the cases where clival defect was eventually found, the reasons outlined for the recurrences included a failure to give surgical consent following the first episode [5], ineffective first surgery [7], inappropriate antibiotherapy course for osteomyelitis [8], and misidentification of the exact leak site [9]. It is our understanding that the patient discussed herein was misdiagnosed following previous episodes. After the diagnosis of clival defect, however, she declined the surgery. A strict follow-up procedure must be mandated in such cases.

Streptococcus pneumoniae, Gemella haemolysans, Hemophilus influenzae, and Neisseria meningitis have all been reported in specific cases. However, in several other cases, the microorganism was not mentioned. With the exception of postoperative meningitis, $S$. aureus in bacterial meningitis is rarely found $[14,15]$. In the majority of cases, S. aureus reaches the meninges via bacteremia from a non-cranium source, such as endocarditis, epidural abscess, and skin or soft tissue

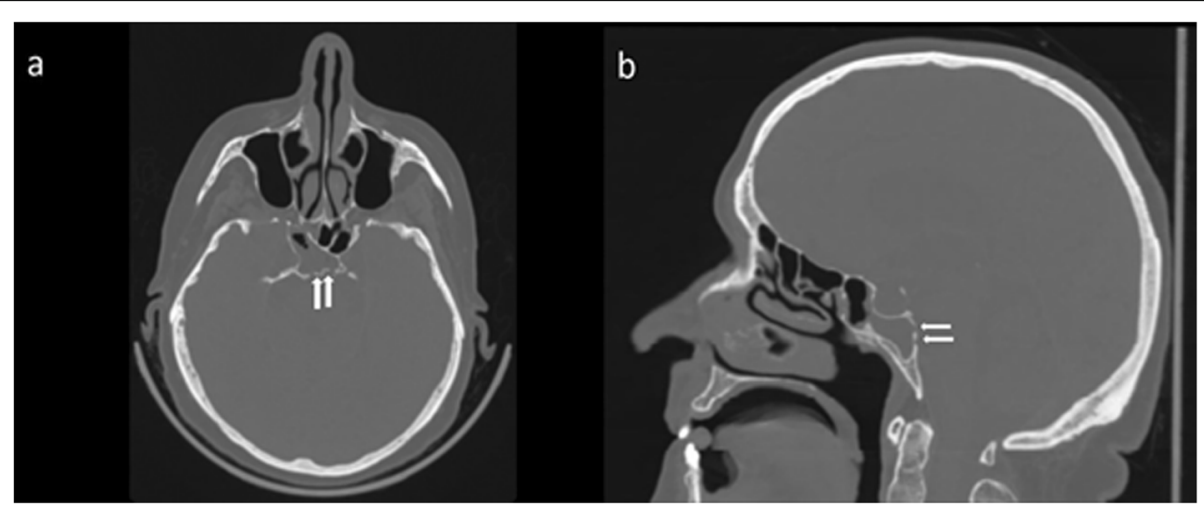

Fig. 1 Axial (a) and sagittal (b) reformatted computerized tomography on bone window reveals a fluid-filled pneumatized clivus with tiny bone defects at the posterior margin (arrows) 


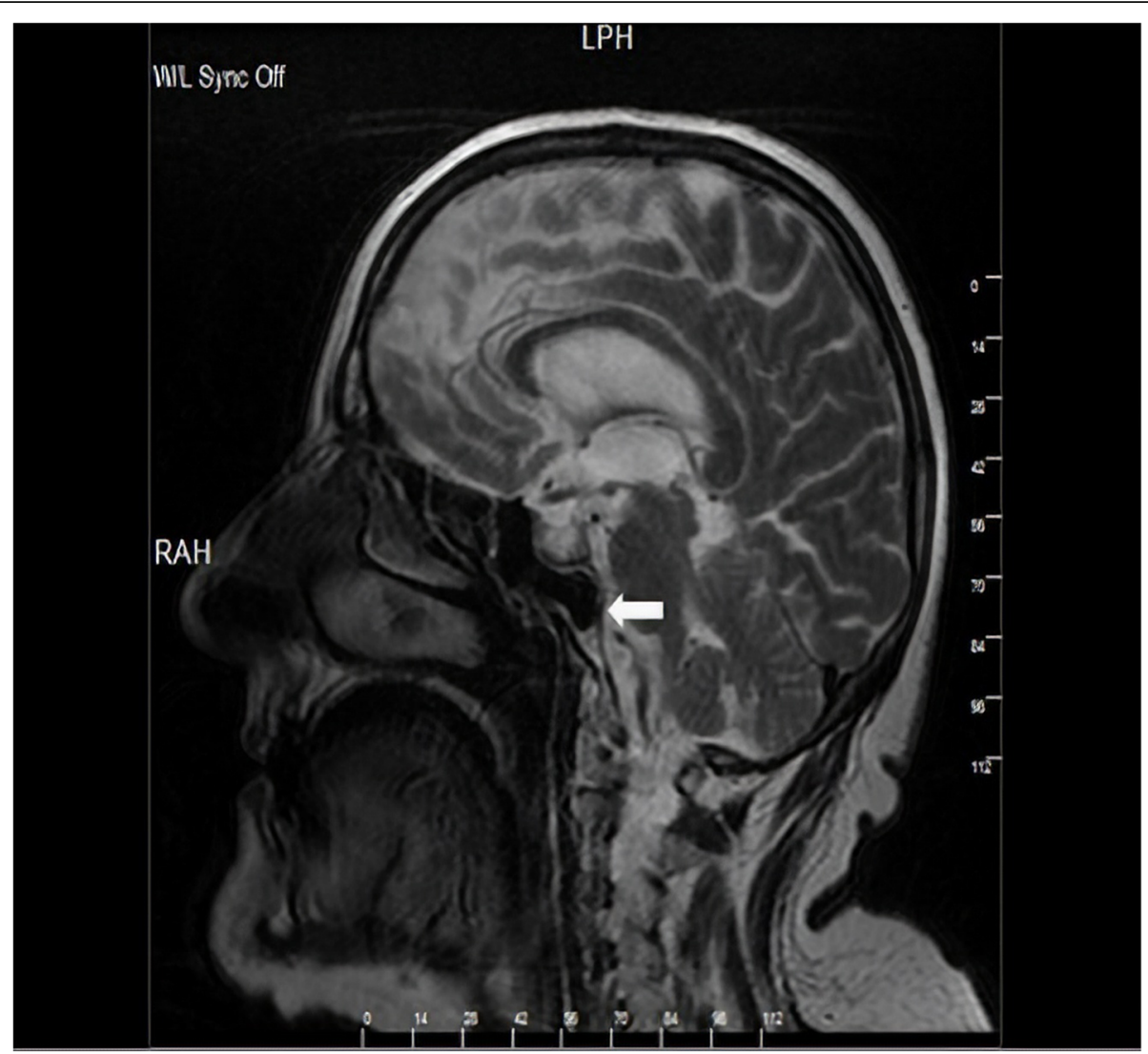

Fig. 2 Sagittal T2-weighted magnetic resonance image shows excessive pneumatization of the clivus (arrow)

Table 1 Case reports of clivus defects with the complication of meningitis in adults

\begin{tabular}{|c|c|c|c|c|c|c|}
\hline Reference/year & Age/gender & Anatomical defect & Cause & $\begin{array}{l}\text { Microorganism } \\
\text { isolated in CSF }\end{array}$ & $\begin{array}{l}\text { Surgical } \\
\text { treatment }\end{array}$ & $\begin{array}{l}\text { Recurrent } \\
\text { meningitis }\end{array}$ \\
\hline [11] / 1995 & $53 / F$ & $\begin{array}{l}\text { Bone defect in the superior third } \\
\text { of the clivus }\end{array}$ & S-CSF-L & Unknown & EET & No \\
\hline [11] / 1995 & 43/M & 3-mm bone defect in the clivus & S-CSF-L & N. meningitidis & EET & No \\
\hline [13] / 2007 & $36 / F$ & Small bone defect of the clivus & S-CSF-L/Marfan syndrome & Unknown & EET & No \\
\hline [12] / 2008 & $50 / \mathrm{M}$ & The mid-clival bony defect & S-CSF-L & Unknown & EET & No \\
\hline [8] / 2013 & $69 / F$ & $\begin{array}{l}\text { Clival erosion and trabecular } \\
\text { thinning }\end{array}$ & Periodontitis (osteomyelitis) & G. haemolysans & Dental procedures & Yes \\
\hline [5] / 2015 & $60 / F$ & $\begin{array}{l}16 \times 9 \times 4 \mathrm{~mm} \text { bone defect within } \\
\text { the posterior clival framework }\end{array}$ & S-CSF-L & Unknown & EET & Yes \\
\hline [10] / 2017 & 38/M & $\begin{array}{l}3 \times 4 \mathrm{~mm} \text { circular bone defect in } \\
\text { the middle of the clivus }\end{array}$ & Trauma (clivus fracture) & S. pneumoniae & EET & No \\
\hline [7] / 2017 & $64 / F$ & $\begin{array}{l}\text { Clival defect with CSF leak into } \\
\text { the sphenoid sinus }\end{array}$ & S-CSF-L & Unknown & EET & Yes \\
\hline [9] / 2017 & $55 / F$ & Midline clival defect & S-CSF-L & Unknown & SRTR & Yes \\
\hline [6] / 2017 & $52 / F$ & $\begin{array}{l}2 \mathrm{~mm} \text { defect in the superior } \\
\text { third of the clivus }\end{array}$ & S-CSF-L & H. influenzae & EET & No \\
\hline [6] / 2017 & 69/M & $\begin{array}{l}4 \mathrm{~mm} \text { defect in the posterior wall } \\
\text { of the clivus }\end{array}$ & S-CSF-L & Unknown & EET & No \\
\hline
\end{tabular}

F female, M male, CSF cerebrospinal fluid, S. aureus Staphylococcus aureus, S. pneumoniae Streptococcus pneumoniae, G.haemolysans Gemella haemolysans, H. influenzae Haemophilus influenzae, N. Meningitidis Neisseria meningitidis, S-CSF-L spontaneous CSF leakage, EET endoscopic endonasal transsphenoidal surgery, SRTR sublabial rhinoseptal transsphenoidal repair 
infections. Direct contagious spread from a colonized skull bone in the presence of CSF leakage is unusual. Some case reports have cited $S$. aureus in the etiology of recurrent bacterial meningitis. The risk factors in these cases include ventriculoperitoneal shunts and dermal sinus tract resulting from epidermoid cyst [16, 17].

Neither of these risk factors was identified in our case. However, the administration of PPSV23 to our patient following her second episode can be described as a risk factor due to the altering of colonization in the sinuses. Some studies have also shown that the nasopharyngeal carriage of $S$. aureus is increased following the widespread usage of the pneumococcal vaccine $[18,19]$. It could be noted that increases in the relatively rare microorganism of meningitis might arise from vaccinations for the more common bacterial agents.

\section{Conclusion}

S-CSF-L from the clivus is a rare condition that can cause recurrent meningitis. With the presence of rhinorrhea, detailed radiological imaging should be performed to detect possible CSF leak. Following the administration of an appropriate agent-specific antibiotherapy and the stabilization of the patient, removal of anatomic risk factors should be considered to prevent recurrences. To date, the endoscopic endonasal approach presents the most effective option.

\section{Abbreviations \\ CSF: Cerebrospinal fluid; EET: Endoscopic endonasal transsphenoidal surgery; F: Female; G. haemolysans: Gemella haemolysans; H. influenzae: Haemophilus influenzae; M: Male; N. meningitidis: Neisseria meningitidis; PPSV23: 23-Valent Pneumococcal Polysaccharide Vaccine; S. aureus: Staphylococcus aureus; S. pneumoniae: Streptococcus pneumoniae; S-CSF-L: Spontaneous cerebrospinal fluid leakage; SRTR: Sublabial rhinoseptal transsphenoidal repair; WBC: White blood cell}

\section{Acknowledgements}

Not applicable.

\section{Authors' contributions}

ANE and RE were involved in giving care to the patient and wrote the manuscript. BB interpreted the images and contributed to the diagnosis. FA developed the primary concept and designed the manuscript. HV supervised the authors. All authors read and approved the final manuscript.

\section{Funding}

No funding.

\section{Availability of data and materials}

Please contact the corresponding author for additional data and images.

Ethics approval and consent to participate

Not applicable.

\section{Consent for publication}

A written informed consent was obtained from the patient.

\section{Author details}

'Department of Infectious Diseases and Clinical Microbiology, Istanbul Medeniyet University, Istanbul, Turkey. ${ }^{2}$ Department of Public Health, Epidemiology Subsection, Dokuz Eylul University School of Medicine, Izmir, Turkey. ${ }^{3}$ Department of Radiology, Istanbul Medeniyet University, Istanbul, Turkey.

Received: 8 August 2019 Accepted: 16 October 2019

Published online: 13 November 2019

References

1. Tebruegge $M$, Curtis N. Epidemiology, etiology, pathogenesis, and diagnosis of recurrent bacterial meningitis. Clin Microbiol Rev. 2008;21(3):519-37.

2. Van Zele T, Kitice A, Vellutini E, Balsalobre L, Stamm A. Primary spontaneous cerebrospinal fluid leaks located at the clivus. Allergy Rhinol (Providence). 2013;4(2):e100-4.

3. Pagella F, Pusateri A, Matti E, Zoia C, Benazzo M, Gaetani P, et al. Endoscopic management of spontaneous clival cerebrospinal fluid leaks: case series and literature review. World Neurosurg. 2016;86:470-7.

4. Loew F, Pertuiset B, Chaumier EE, Jaksche H. Traumatic, spontaneous and postoperative CSF rhinorrhea. Adv Tech Stand Neurosurg. 1984;11:169-207.

5. Oleś K, Składzien J, Betlej M, Chrzan R, Mika J. Spontaneous cerebrospinal fluid leak at the clivus. Wideochir Inne Tech Maloinwazyjne. 2015;10(4):593-9.

6. Codina Aroca A, Gras Cabrerizo JR, De Juan DM, Massegur SH. Spontaneous cerebrospinal fluid fistula in the clivus. Eur Ann Otorhinolaryngol Head Neck Dis. 2017;134(6):431-4.

7. Asad S, Peters-Willke J, Brennan W, Asad S. Clival defect with primary CSF rhinorrhea: a very rare presentation with challenging management. World Neurosurg. 2017; 106:1052.e1-4

8. Hayashi T, Uchiumi H, Yanagisawa K, Ogawa Y, Handa H, Tsukamoto N, et al Recurrent Gemella haemolysans meningitis in a patient with osteomyelitis of the clivus. Intern Med. 2013;52(18):2145-7.

9. Tandon V, Garg K, Suri A, Garg A. Clival defect causing primary spontaneous rhinorrhea. Asian J Neurosurg. 2017;12(2):328-30.

10. Tohge R, Takahashi M. Cerebrospinal fluid rhinorrhea and subsequent bacterial meningitis due to an atypical clival fracture. Intern Med. 2017; 56(14):1911-4.

11. Coiteiro D, Távora $L$, Antunes JL. Spontaneous cerebrospinal fluid fistula through the ClivusReport of two cases. Neurosurgery. 1995;37(4):826-8.

12. Ahmad FU, Sharma BS, Garg A, Chandra PS. Primary spontaneous CSF rhinorrhea through the clivus: possible etiopathology. J Clin Neurosci. 2008; 15(11):1304-8.

13. Ramos A, García-Uría J, Ley L, Saucedo G. Transclival cerebrospinal fluid fistula in a patient with Marfan's syndrome. Acta Neurochir. 2007;149(7):7235 discussion 725.

14. Aguilar J, Urday-Cornejo V, Donabedian S, Perri M, Tibbetts R, Zervos M. Staphylococcus aureus meningitis: case series and literature review. Medicine (Baltimore). 2010:89(2):117-25.

15. Pintado V, Meseguer MA, Fortún J, Cobo J, Navas E, Quereda C, et al. Clinical study of 44 cases of Staphylococcus aureus meningitis. Eur J Clin Microbiol Infect Dis. 2002;21(12):864-8.

16. Cherian A, Baheti NN, Easwar HV, Nair DS, lype T. Recurrent meningitis due to epidermoid. J Pediatr Neurosci. 2012;7(1):47-8.

17. Spanu T, Romano L, D'Inzeo T, Masucci L, Albanese A, Papacci F, et al. Recurrent ventriculoperitoneal shunt infection caused by small-colony variants of Staphylococcus aureus. Clin Infect Dis. 2005;41(5):e48-52.

18. Devine VT, Jefferies JM, Clarke SC, Faust SN. Nasopharyngeal bacterial carriage in the conjugate vaccine era with a focus on pneumococci. J Immunol Res. 2015;2015:394368.

19. Ebruke C, Dione MM, Walter B, Worwui A, Adegbola RA, Roca A, et al. High genetic diversity of Staphylococcus aureus strains colonising the nasopharynx of Gambian villagers before widespread use of pneumococcal conjugate vaccines. BMC Microbiol. 2016;16:38.

\section{Publisher's Note}

Springer Nature remains neutral with regard to jurisdictional claims in published maps and institutional affiliations. 